\title{
THE CASTLE OF ASSORO: THE INTEGRATED SURVEY FOR THE KNOWLEDGE AND CONSERVATION OF RUINS
}

\author{
A Versaci ${ }^{1}$, A. Cardaci $^{2}$, L.R. Fauzìa ${ }^{1}$, M. Russo ${ }^{3}$ \\ ${ }^{1}$ Faculty of Engineering and Architecture, University of Enna 'Kore', Italy - (antonella.versaci, luca.fauzia)@unikore.it \\ ${ }^{2}$ Dept. Engineering and Science Applied, University of Bergamo, Italy - alessio.cardaci@ unibg.it \\ ${ }^{3}$ Independent researcher, Enna, Italy - michele16.91@ hotmail.it
}

KEY WORDS: Integrated 3D survey, Conservation, Restoration, Assoro, Enna

\begin{abstract}
:
Assoro is an ancient city located in the heart of Sicily. Its fame in the Middle Ages is linked to the strategic location of its primitive nucleus placed at the top of Monte Stella. The fortified site allowed, in fact, both the defence of the surrounding territory and the control of the internal crossings of the island, from east to west. Today, the ruins of the castle, still visible in the highest part of the city, are enclosed in a large urban park that neither enhances nor facilitates its understanding. Actually, the knowledge of the monument is very incomplete due to the lack of documentary sources. To compensate these gaps new investigations were undertaken. Survival masonries were examined by a careful visual investigation and a deep survey, both for the stratigraphic, material and degradation aspects, carried out through the integrated use of active and passive sensors instruments. The critical analyses arising from the appropriately constructed $3 \mathrm{D}$ models and the photo-realistic orthographic projections with the mapping of the different constructive phases, the building materials and decay, was laid as the foundation of the cognitive process aimed at the establishment of a sustainable conservation and valorisation project. The programme has also foreseen the realisation of some archaeological coverings and the improvement of the whole park fruition, through paths that aim to both ensure easier access to some rocky archaeological areas currently difficult to reach and greater integration and permeability, between the historic urban fabric and the park.
\end{abstract}

\section{INTRODUCTION}

Perhaps even more than other Italian regions, Sicily is a land of castles. We only need to look at the denomination of many of its cities to appreciate it (CRICD, 2001). An immense heritage made up of fortresses located in or near urban centres, an extensive system of coastal towers and several fragments of town fortifications, which reflect the long history of the Island, its strategic role at the core of the Mediterranean Sea and then of the civilizations of the Ancient World.

The extraordinary variety and multiplicity of this legacy narrate the cosmopolitan historical development that Sicily can boast and disclose the relationships among man and places, between the population of towns and villages and the peoples that have occupied it and shaped its social and cultural character.

A vast production that since the Phoenicians - which more than three thousand years ago, enclosed Mozia, Solunto and Palermo by defensive walls to transform them in sentinels over the sea crosses the Greek age and its imposing Syracuse fortifications, goes on throughout the Middle Ages and the extraordinary empire of Frederick II, to end with a big flourishing during Spanish domination. Military architectures, which language results from the different contributions that have occurred over time, the exchanges of culture, workers, materials, the construction models that have been superimposed on the search for the 'perfect' castle.

Most of these assets, important evidence in the Sicilian landscape, now appear to be in a state of decay and neglect, damaged by the inevitable passage of time and the absence of conservation and maintenance activities. Their knowledge is often incomplete, despite the extent of research conducted in the historical and architectural field, due both to the lack of archival sources and to other problems of a methodological nature, i. e. the shortage of studies on stratigraphy and masonry techniques at the regional level or some difficulties in their interpretation.
Actually, archaeological excavations are very often neglected in the castle studies and even more in the projects related to their restoration or re-functionalization, probably because of the notable scientific and economic commitment required. In other cases, however, the decision to refurbish these structures, to ensure their spaces for new uses, has guided interventions carried out without the necessary preventive investigations on both the visible and buried components, so causing the permanent loss of important historical data. Moreover, these architectures are also frequently difficult both to reach due to their impervious location and to investigate because of their extent, size and spatial configuration (in general, rich in stratifications).

Problems that - despite the praiseworthy experiences of classification conducted by the Sicilian Region and the regional section of the Istituto Italiano dei Castelli - have made it difficult a reliable and exhaustive cataloguing, together with the inadequacy of surveys, not always carried out in a systematic and coherent manner and/or marked by adequate levels of precision and correctness. Recognitions that, on the contrary, should be able to highlight, in addition to the strictly metric aspects, the peculiar characteristics of the structures, in relation to the soil to which are linked for the material they are made of (Gazzola, 1965); and to read them as 'documents' that tell about the ancient construction techniques, the history and evolution of defensive systems, the siege and combat modes, the capacity of structures resistance and the collapse modalities following events such as the earthquakes (Foramitti, 2004). This in order to make credible comparisons and to define programs aimed at their sustainable safeguarding (Fallavolita \& Ugolini, 2017).

With this in mind, a series of new investigations on the castle patrimony of Central Sicily was launched by the Laboratory of Diagnostics and Restoration of Architectural and Cultural Heritage of the Kore University of Enna, in collaboration with the Lab_S.A.B.E. of the University of Bergamo. 
A research program that, based on solid technical and scientific quality criteria, has concerned, between others, the remains of the castle of Assoro. A little-known but yet interesting monument, both for the numerous (but poorly preserved) traces of a glorious past that it embodies and because of its close relationship with the territory. A site that deserves special attention, but that, despite the population's regard, has experienced long episodes of abandonment and depredation $(A V)$.

\section{THE CASTRUM ASARI: FROM THE ANTIQUITY TO NOWADAYS}

\subsection{Historical background}

Located in the centrum of Sicily, the castrum Asari stands on a natural stronghold placed at the top of the Monte Stella, inhabited since the protohistoric era, as evidenced by Diodorus Siculus, Cicero and Pliny the Elder. Thanks to its strategic position, it has certainly assumed notable importance not only as a place of control and defence of the surrounding territory but also as a crossing point between the east and the west of the Island.

With great probability, in the Hellenic period, the hill hosted the acropolis of which some relics, today almost completely illegible, were identified in 1924 by the archaeologist Luigi Bernabò Brea (Bernabò Brea, 1947) and in the 1960s by JeanPaul Morel, an archaeologist from the French School of Archaeology in Rome (Morel, 1964). In Roman times, the city of Assorum lived a wealthy period, as located at the crossroads of intense trade; benefiting from the title of Civitas Foederata, it enjoyed freedom against the severe harassment of the Roman Empire.

In the Byzantine age, the site was surrounded by a fortification, later destroyed and reconstructed by Arabs that in 939 conquered and included it in the Taifa of Qasr Jani (Enna). From the same Byzantine period, date back some artificial caves discovered by the archaeologist Paolo Orsi in 1916 near the castle.

Taken by the Normans in 1061, the citadel moved, by a deed of sale signed by Roger II, to the bishop of Catania who acquired the feudal right. Then he went to the miles Scaloro degli Uberti and in 1340 , during the long period of conflicts between proAngevins and pro-Sicilian factions, was confiscated and entrusted to the Duke of Randazzo, together with Gatta and Condrà hamlets (Amico, 1855).

In 1347, the Uberti was forgiven and the feuds reverted to him but a few years later, during a dramatic siege by the insurgent population, the fortress was damaged and he lost his life. Given back to the royal court, Assoro was bestowed in 1364 by Frederick IV to Matteo d'Aragona, but having died the same year without leaving heirs, after a brief concession to Andrea degli Uberti, it went to Antonio Moncada, This latter, accused of plotting against the crown, the city was then granted by Martino I to the Catalan family of the Valguarnera.

In the next years, the castle, already semi-abandoned, was employed as a prison. Certainly, further damage occurred following the earthquake of 11 January 1693, which affected Central-Eastern Sicily. In 1803, Saverio Landolina, the Royal Guardian of the Antiquities of Val Demone and Val di Noto sent a letter addressed to Pietro Romano, custodian of antiquities, reproaching him for not having prevented the sale and demolition of parts of the walls, perhaps reused also for the building of his own palace. In 1974, the Riccioli family bought the land with the ruins and a few years later, gave back the castle to the city.
This area was held by Germany during the Allied Sicilian Campaign in World War II. The Canadian unit finally released the site, considered an almost impregnable position for months, during a night raid that caused it additional damages to the structure.

The area remained abandoned until the end of the $20^{\text {th }}$ century when an urban park was built around the vestiges of the castle which were partly consolidated - and the traces of both the fortifications and the ancient acropolis. So destroying what was supposed to be the ancient pomerium and relegating the ancient fortress to the mere role of silent scenery of a new collective space, however unable to contextualize the monument in the present-day world $(A V)$.

\subsection{The castle today: analysis of its architectural features}

Medieval fortifications, as in many cases in the area of Central Sicily, exploit the rock outcropping in an elegant succession of volumes carved into the rock and built in masonry. Even in this case, the assorino fortress follows the irregular trapezoidal form of the rocky pedestal that overlooks the western slope of the town. The entire surviving complex adapts to the orography of the terrain and consists of spaces, placed at different heights, carved into the rock itself or built on it. In particular, a full circular tower emerges at the end of a wall (figure 1).

Recent research has allowed updating the knowledge on the monumental history of the city, as outlined by the rare literature and mainly by the writings of Giovanni Gnolfo. The study is founded on a $16^{\text {th }}$-century bird's eye view, kept at the Biblioteca Angelica in Rome. This is the most ancient iconographic evidence of Assoro, produced within a project - not published, but almost ready for printing - of Atlante of the Southern cities, planned by Angelo Rocca. The Augustinian bishop had taken advantage of its visitationes in the Kingdoms of Naples and Sicily to collect plans of their cities. Among the 77 urban views now finally published (Muratore \& Munafò, 1991) we find that of Assoro in 1584: an interesting portrait of the town as it was at the time, showing its urban morphology and monuments.

The comparative analysis between the image, the historical documentation, and the today's place has permitted reconstructing a possible configuration of the castle: a tripartite building on two and three levels, with exposure to the south and minimal openings, overlooking a small entrance dominating the current access with the vertical tunnel passageway. An imposing curtain wall, between the southern fortress and the current circular tower to the northeast, completes the western front, so probably denying the hypothesis of a castle typology characterized by an albarrana tower that for a long time was the most accredited one (Magnano di San Lio \& Pagello, 2004).

Today, the fortress lies in a state of rudeness that prevents it from being correctly understood. Only some imposing perimeter walls can be distinguished; one of these, facing towards the valley, has several holes, probably traces of ancient wooden supporting beam elements. An underground hallway, containing a staircase, connects two different levels. Other rooms, also carved into the rock and cross-vaulted, have drainage channels at the bottom.

Its physical substance is characterized by a considerable stratigraphic complexity; the absence of reliable documentation and the precarious state of conservation has highly affected the full comprehension of the monument, especially with reference to its spatial structure, the material and constructive features, and the relations between its different elements. A place of mysterious origins, the castle is so valuable for the history of Sicily and for the local people who want to defend but at the same time does not really know it. This privileged place earns, actually, to regain its central role and through concrete actions 


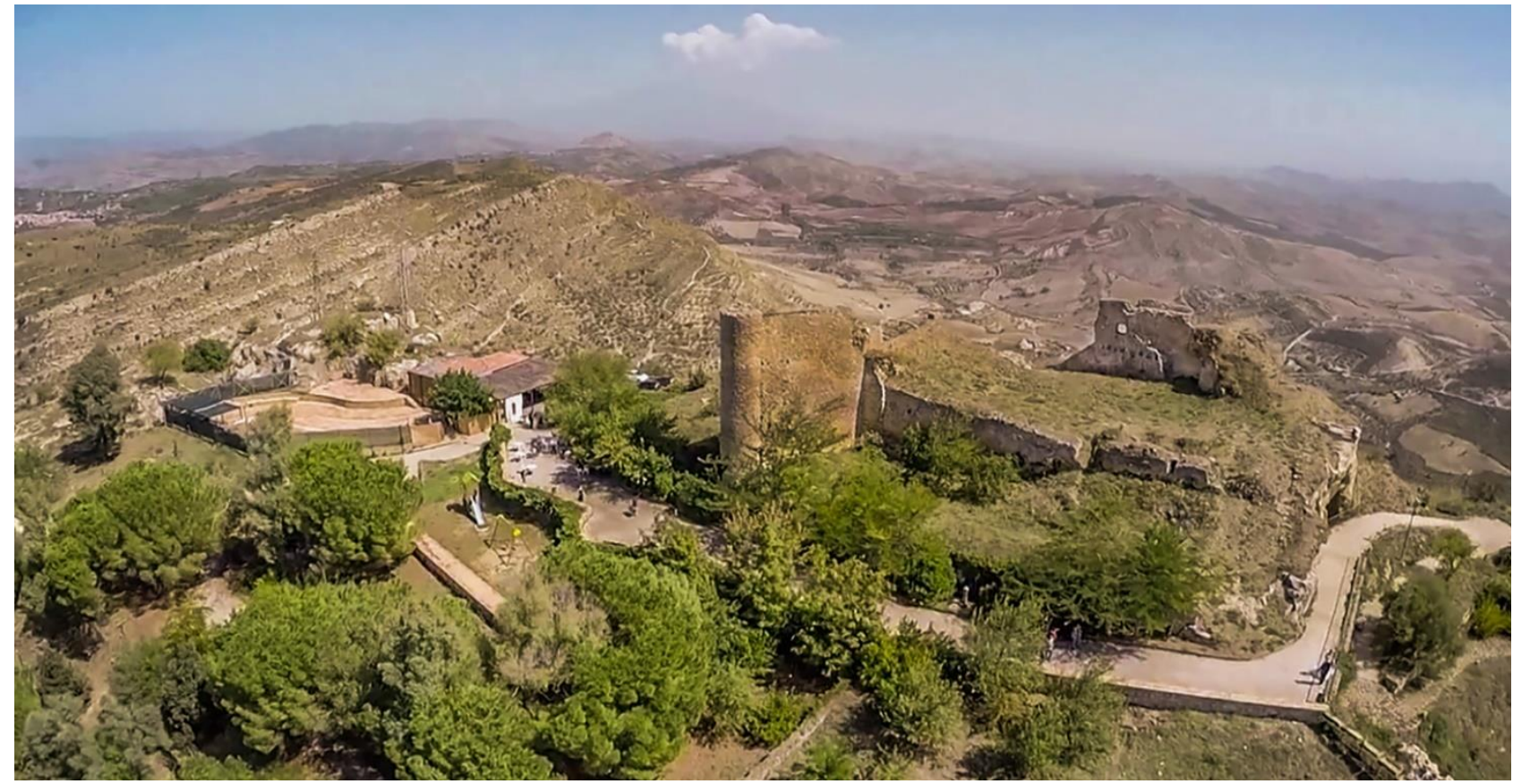

Figure 1. The ruins of Assoro castle, today

and tools, to make up with a population that needs to become more sensitive to the importance of recovering its roots.

To this end, the authors of this paper have carried out new factfinding investigations to provide research community - through a comparative reading of the historical sources, the archaeological stratigraphy and the other material signs - new means to deepen their own research, to prove hypotheses and substantiate the necessary design choices aimed at the revitalization of the monument.

After having ascertained the lack of a graphical reconstruction metrically correct and critically characterized of the front walls, re-examined all the bibliography and archival sources available, acquired the most recent scientific literature on the medieval castles of southern Italy, the starting point of the new investigation has, therefore, concerned the execution of an accurate geometric survey $(A V)$.

\section{FROM THE KNOWLEDGE TO THE CONSERVATION AND VALORISATION PROCESS}

\subsection{The indispensable role of the integrated survey}

The knowledge of historic buildings requires a multidisciplinary approach, to integrate the technical capabilities of the engineering with the sensitivity of the sciences of history and archaeology. On these assumptions, have been based the research activities undertaken on the castle of Assoro. They have merged the historical and stratigraphic investigation, with the metric, material and decay analyses.

The integrated survey, conducted with both different technologies for the acquisition of metric data and qualitative information on materials and degradation phenomena, and for processing procedures, offers the opportunity to support the awareness of the state of conservation of the built heritage in a rapid and effective manner, for the purpose of its protection and enhancement (Versaci \& Cardaci, 2011).

The traditional survey supported by the use of active (3D laser scanner) and passive sensors (digital Photogrammetry), if completed by the information taken by aerial shots, now possible thanks to the help provided by small drones, can ensure three-dimensional models of high geometric reliability and high chromatic quality. The integration of the different measurement methods, together with adequate processing and homogenization of the information, allows the rapid creation of virtual models of the architectures and their surroundings. A methodological practice of investigation, which complies with the criticalities' mapping of buildings in the state of ruins, such as the one here considered, which cannot be understood, except by analysing the territorial context in which they are inserted.

In the last decade, the joint use of several survey techniques appeared very laborious, but recently, thanks to new platforms more flexible and efficient, the sharing of multiple models in a single environment - points and/or polygonal meshes - has imposed itself because a competitive technology, able to provide 'complete' digital models. The parts occluded and hidden from the 'ground' vision are captured by an 'airborne' sensor placed on a small drone very easy to fly.

However, the activity planning and the direct contact with the monument (the so-called 'live drawing') remain the indispensable preliminary steps to carry out work in a conscious way, well focused on the objectives to be achieved. The preliminary inspection undertaken in the different hours of the day (in order to check the lighting conditions), the drafting of sketches and functional diagrams (figure 2), the annotation of the first impressions about the volumetric articulation and surfaces, the construction techniques, the materials and their condition, always has a fundamental importance for the understanding of the building (Purini, 1996).

The surveying program was therefore established with extreme care and great attention to the complexity of the site, which today presents only a few visible parts and insists on a large archaeological deposit, in many parts not excavated. The need to place and file the surviving fragments present in the area for documentary cataloguing (both through their detailed representation and with hypertexts containing their position, a brief description and photographic documentation) has highly conditioned the activities. The remains disseminated in the urban park, in addition to the ruins of the castle, are in fact, numerous and include parts of other ramparts, fragments of columns and entablatures, systems for collecting water, caves 
and underground areas, including a rupestrian oratory. Consequently, the choice of the resolution and the metric accuracy of the final outputs asked for a specific and careful study, in order to seek a fair compromise between costs (time and resources) and quality. In fact, if a single high-resolution model would have made it possible to include every detail of the complex, it would have been difficult to consult; on the other hand, a low-resolution model, although more manageable, would have lost many details (figure 3 ).

It was, therefore, decided to build a multi-scale system, including in a single georeferenced environment, both very accurate and higher resolution models - reconstructed from 3D laser scanning acquisitions, terrestrial Photogrammetry and aerial images from drones flying at low altitude - and lower quality models, obtained by UAV systems. This has therefore permitted the production of the orthophotos of the wall façades at the 1:50 scale, necessary for the preliminary analyses and the drafting of the conservation project, and at the same time, the modelling of the DEM surfaces of the whole area for the establishment of a refurbishment project related to the urban park $(A C)$.

\subsection{The combined use of $3 D$ laser scanning and digital Photogrammetry}

The geometric accuracy of the final model was guaranteed and verified by means of the $3 \mathrm{D}$ laser scanning survey; it has, in fact, constituted the network for the subsequent overlapping of photogrammetric artefacts. The construction of a global and multi-scale model required two different measurement methods; very dense clouds (with short distance stations) were acquired in the architectural survey and, at the same time, more sparse clouds (with stations placed at high distances) for the metric estimate of the embankments and open areas (Baletti et al., 2005).

In particular, for the production of the dense clouds, the average distance between scan stations was approximately 5 meters; the resolution of the instrument was chosen in order to ensure an average point density of less than 5 millimetres and an overlap of not less than 50-60\%. Measurements were conducted by
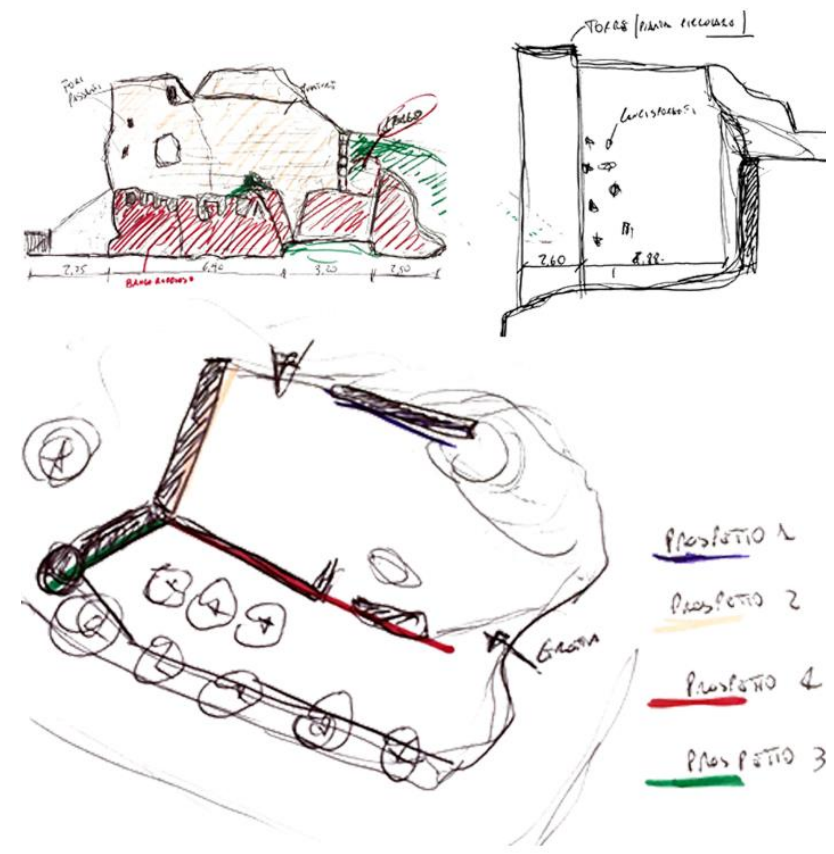

Figure 2. Sketches and functional diagrams of the ruins of the Assoro castle for the surveying planning

quickly moving the device at the end of each scan and without the use of targets, for time optimization, even with a high number of acquisitions. For the terrain, scans were carried out with distances between the stations varying between 15 and 20 meters and with an average point density of a few centimetres. In this case, it was necessary to use targets to georeference the clouds in a single system, also to avoid incurring inaccuracies due to reduced overlapping values. Targets were also functional to the drone survey; they were used both as Ground Control Points (GCP) to orient and scale photogrammetric models and as Quality Control Points (QCP) to verify the accuracy of the restitution (the difference between the coordinates measured in
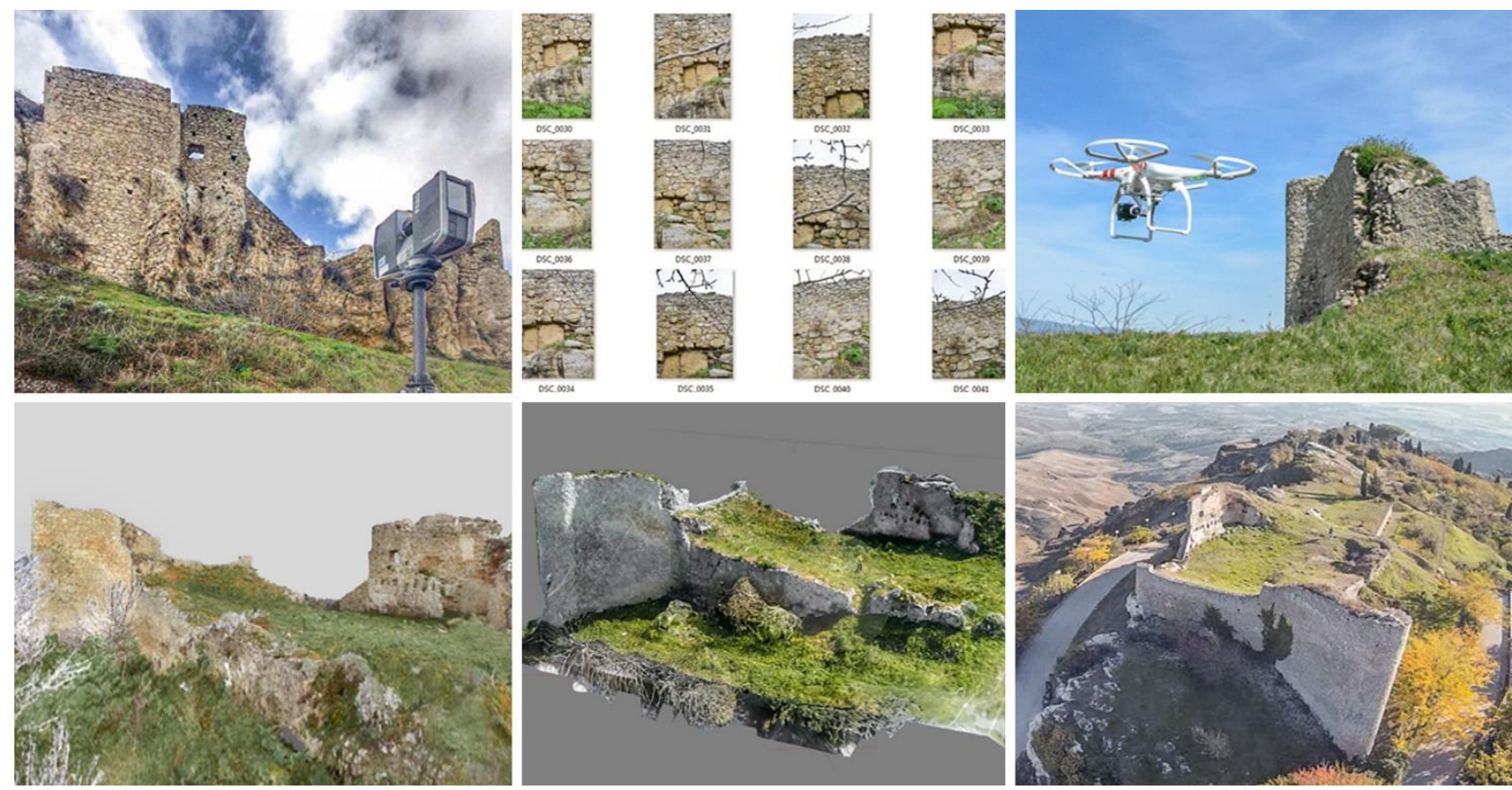

Figure 3. The integrated survey: 3D laser scanning and digital terrestrial and UAV photogrammetry 
the field with the laser instrument and the coordinates obtained by the 3D Image-Based Reconstruction software with drone were actually employed for an assessment of the accuracy of the photogrammetric model).

The single scan processing was performed by Faro® Scene. Two distinct global point clouds were created: the first one with the superimposition of the colourimetric data, the second only in simple reflectance values. The consultation of the points model only benefits if they are coloured, as it is easier to recognize the various parts and their processing. The colour datum, however, constitutes an element not necessary for the creation of a homogeneous structure to superimpose the photogrammetric model; in this case, it was decided to use non-coloured clouds, properly homogenized, decimated and free of overlapping points.

The spatial textures, validated and verified thanks to the information obtained by the 3D laser scanner survey, were created through the digital photogrammetric technique (Reiss et al., 2016). The use of appropriate images has allowed the creation of virtual artefacts thanks to the use of the modern 3D Image-Based Reconstruction platforms. The study of the photographic sockets in the best lighting conditions and the application of the 'good photographer' rules concerning the choice of the shooting modes, the appropriate diaphragms and times, the correct white balance and the ISO value, marked the first step of the photogrammetric survey. A good model can in fact, only be obtained from excellent image sets, appropriately got by multiple HDR shots and rigorously and consciously developed from raw data (Suma et al., 2016).

Basic instructions with which were taken all the photos 'from the ground' but not, unfortunately, those by the drone. In this case, both JPG-type images were used to complete the architecture models, such as the castle risers, and full HD videos for the park area. A semiautomatic camera, like that of a small UAV, does not, in fact, consent the adjustments allowed by a reflex positioned on a tripod; the same quality of the images has, alas, been inferior and this was the cause of less accurate models and with lower resolution.

In the specific case, in order to optimize the operations, a manual fly was chosen to position the drone a short distance from the ruins and to guarantee worthy images with a very high overlap. The shots were taken both with the camera placed horizontally (for the prospects) and vertically (for the wall crests). Instead, an automatic flight was selected for surveying the park, preferring videogrammetry to the individual shots; the flight was designed by choosing a take-off altitude of about 20 meters to have a height of about 50-60 meters on the ground of the most depressed parts. The flight planning took into account a $70 \%$ overlap by adjusting the drone's moving speed to the number of frames per second recorded by the camera (Federman et al., 2018).

The image sets, both terrestrial and aerial, were then processed with different software (Agisoft ${ }^{\circledR}$ Photoscan - today Metashape -, Pix4D® Mapper and 3DFlow ${ }^{\circledR}$ Zephyr) to use the best model; Pix4D® Mapper provided excellent results from drone images, the 3 DFlow ${ }^{\circledR}$ Zephyr videogrammetry module proved to be the fastest and most efficient, while Agisoft ${ }^{\circledR}$ Photoscan confirmed to be the most suitable for terrestrial photogrammetry.

The 3DFlow ${ }^{\circledR}$ Zephyr platform was also used for the creation of the global model. The photogrammetric models were imported, assembled and superimposed on the 3D laser scanner's point cloud. The model allowed the graphics rendering, useful to support the material characterization, as well as the stratigraphic and decay mapping $(A C)$.

\subsection{The study of historical mortars as a component of the knowledge process}

In the knowledge process of the Assoro castle, the building stratification was intended as a process of deposition of equally authentic construction phases and for this reason, having historical-documentary value.

Therefore, the aim of the conservation project was not only the maintenance of the material authenticity of the architectural object but also the possibility of understanding the stratigraphic relations between its different constructive moments (Alagna, 2008).

In this sense, the study of the stratigraphy of the walls followed a multidisciplinary approach and performed the analysis typical of the Archaeology of Architecture. Of great help was the work carried out by the integrated survey for the photographic restitution of the surfaces that allowed an 'objective' reading of the material characteristics of the wall structures, so improving their qualitative knowledge.

The macroscopic analysis of the mortars identified in all the castle walls was then a crucial step. Actually, mortars are an important source of information and a reference of great value in support of the study of masonry, since they are materials that cannot be reused and, therefore, can be indicative of the age of construction of the masonry. The analysis made it possible to identify ten mortars' types, with good probability corresponding to different phases of the building's construction and/or subsequent interventions.

For each of them, a sample was taken and a data sheet established - following the model developed by the Archaeology of Architecture Laboratory of the University of Siena (Arrighetti, 2012) - to provide a brief description of the chromatic characteristics, the typology based on its use, the level of cohesion, the relationship and the nature of the binder and the inert, the presence of incongruous elements and degradation phenomena, was produced. Each card was also accompanied by a short descriptive text and a photograph of a significant sample (figure 4).

The mortar cataloguing data sheets were digitized in an XML database, with the creation of special metadata for each information field. They were implemented on a digital HTML platform, from which it is possible to obtain the information collected by interacting directly on the graphic drawings of the castle elevations, in which 'hot points' have been inserted in correspondence with the picking areas $(L R F)$.

\subsection{The stratigraphic mapping and the conservation project}

Although at this stage it was not possible to carry out the necessary chemical, mineralogical, and micro-structural as well as physical and mechanical tests that could provide further essential data about the provenance of the materials used, including binder and sand types, and also about decay products and their correlation with the mortar's conservation state (Santos Silva et al., 2001), the information gathered was very useful to support the recognition - qualitative and quantitative - of the different masonry types.

Masonries were then categorized by comparing samples of about one square meter, chosen based on their build quality and state of preservation and evaluated in accordance with the requirements of the stato dell'arte muraria.

To this phase - obviously still implementable, also through the crossing of data relating to other castle's constituent materials -, followed the individuation of the alterations and degradations of the surfaces, for the evaluation of the conservation status and the identification of the critical factors, which were essential to 

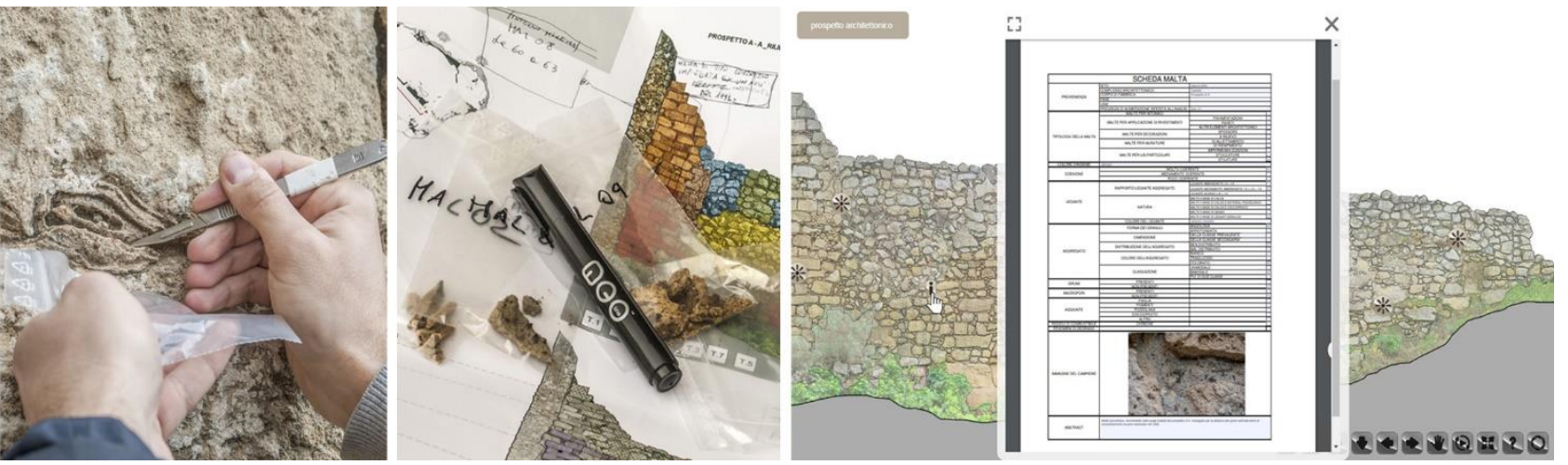

Figure 4. The mortars analysis: collection, cataloguing and identification in wall hangings

address, as a result, a respectful and viable conservation project (figure 5).

The planning of the interventions was, consequently, related to the historical, critical and architectural data emerged from the long cantiere della conoscenza and established to counteract the deterioration phenomena, through targeted and punctual conservation and consolidation actions.

The aim was to preserve the, by now, rare material testimonies of the past, to guarantee their continuity over time, also in order to allow new necessary studies in the future.

With regard to the specific aspect of consolidation, several actions have been envisaged to reinforce all the structures of the architectural artefact that show weaknesses mainly due to collapse or failures.

For the conservation of the stone surfaces and the protection of the wall crests, reference was made to the cultural and technical framework defined by the national and European legal devices, the technical regulations and the Restoration Charters, in an 'active' view of the whole process, ready to be, adjusted, modified, implemented, following the evolution of both the urban and natural landscape and the site's archaeological knowledge.
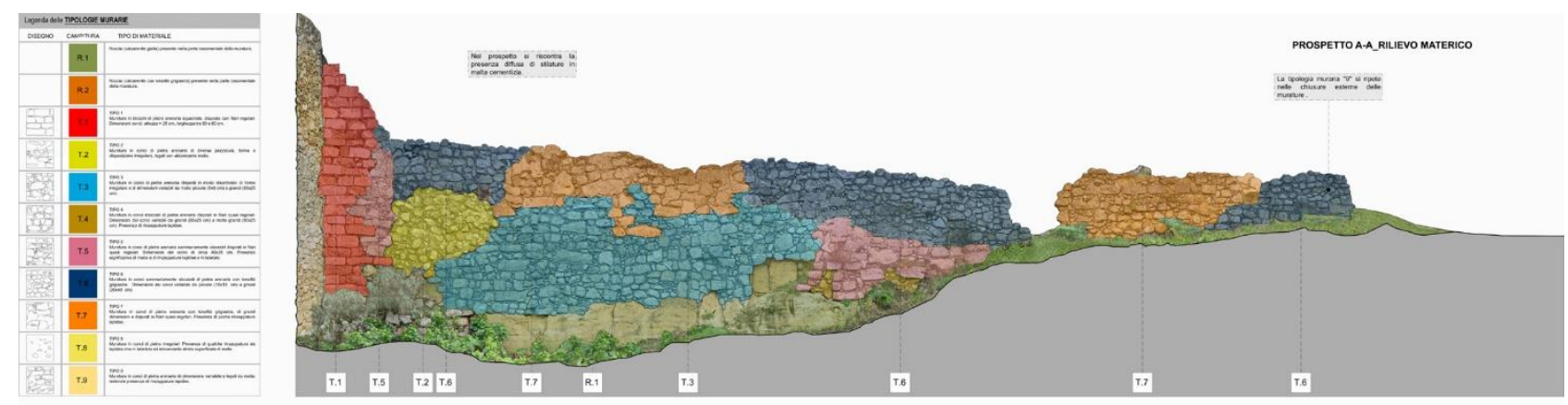
operate softly, by light touches, without disfiguring it, or drying out its deepest meaning (Scudino et al., 2006) but, on the contrary, aimed at amplifying its potential of cultural productivity. In other words, a project not limited to the mere contemplation of the relics, but rather working, on its anthropic and environmental context, in order to assign it, finally, an active and dynamic role in the contemporaneity $(A V)$.

\subsection{The valorisation project: protective shelters for the archaeological remains and new walking paths for visitors}

In line with the conservation program, the valorisation of the entire area was designed as an intervention as much as possible, not invasive. Therefore, it acted through the integration of elements that, at the perceptual level, would not alter the relationships with the pre-existing structures, but contribute to exalt the archaeological remains (figure 6).

To protect the archaeological finds in the southwest area of the urban park from the weather, pollution and uncontrolled anthropic activities, a system of shelters was studied consisting of a steel supporting structure with Corten steel thin slabs.

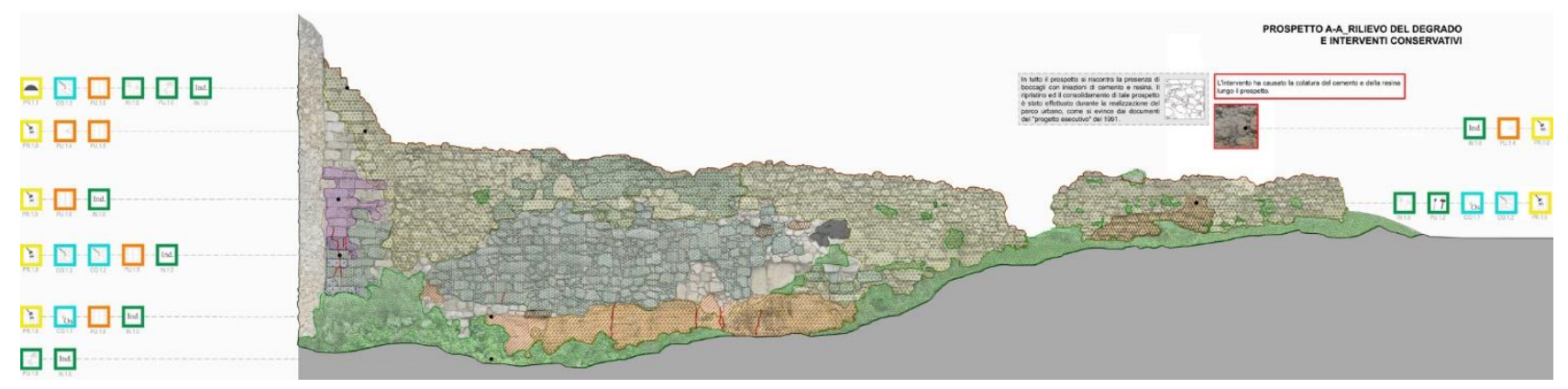

Figure 5. The wall masonry characterisation, the decay mapping and the conservation project 


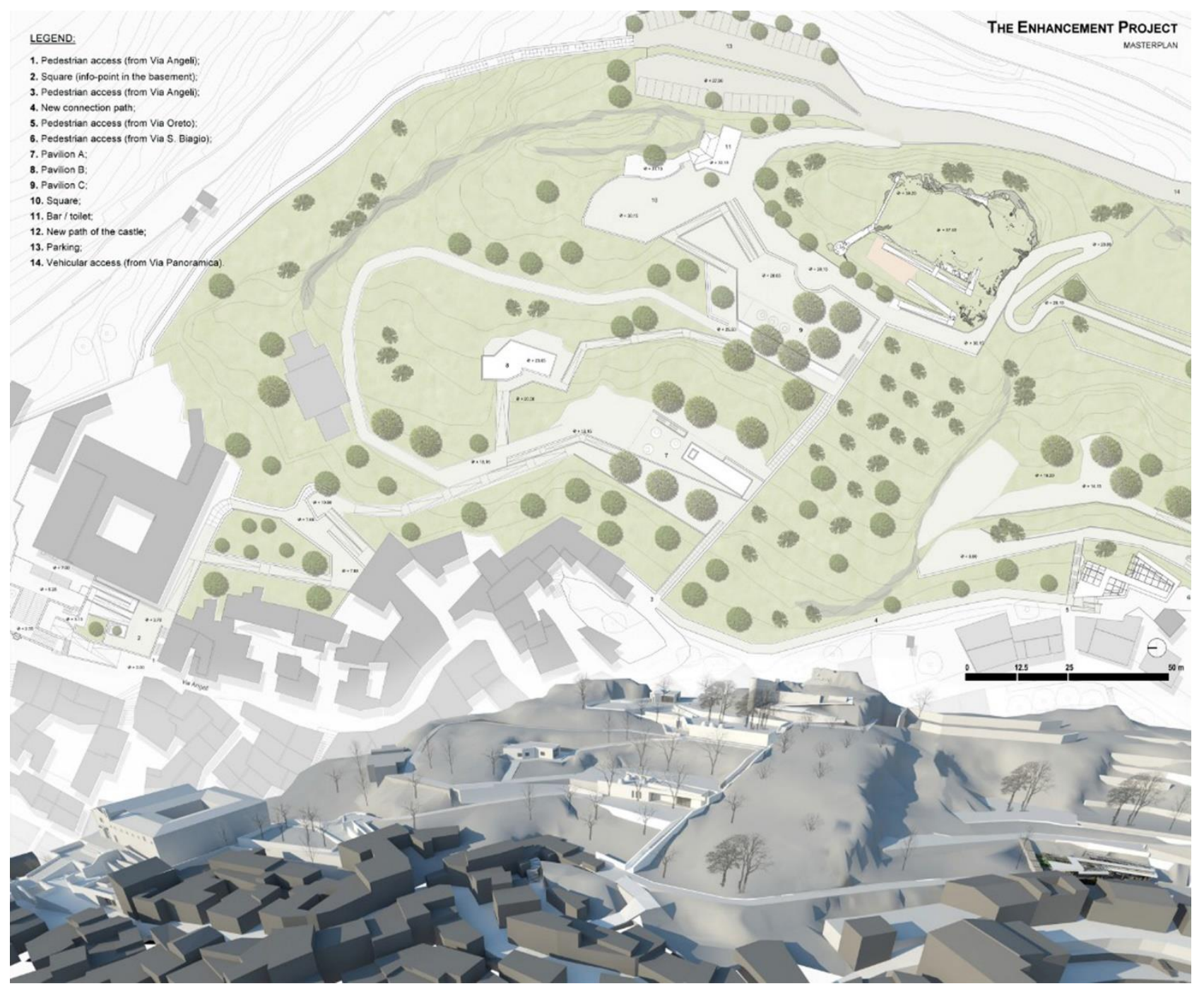

Figure 5. The park enhancement project on the 3D model obtained by the survey campaigns

The project has revised the existing in an interpretive way, providing distinguishable interventions and using different and reversible materials.

Conceptually, it is a visible grid that, through the displacement of some portions of the cladding, follows the traces of the remains, enhancing the perception of internal environments of which today only some wall traces can be read.

The project has also aimed at enhancing the park with some improvements in the fruition aspects. The aim was to allow a close and safe view of the castle, through a process aimed at encouraging the visit by users, offering them the opportunity to discover and interpret its vestiges.

The studies undertaken have shown that there is a lack of sense in the current itinerary, which involves considerable difficulty for the visitor to perceive and understand the relationships between the parties, but also to physically access some areas of the site, particularly interesting from an archaeological point of view.

In order to compensate for these critical issues, new itineraries, inside and around the ruins were established. The absence of relevant parts of the original architectural organism implies the loss or the impracticability of the paths that were once usual.

For this reason, the design has required a critical approach resulting from a thorough knowledge and the comparison between the former and the actual state. In this respect, a didactic character has been attributed to the new path, intended as a low-impact museum element, useful for guiding users with elements that testify to their contemporaneity. Gangways, paths, raised floors, railings and perimeters play the role of directing the 'remains' experience so enhancing the visitor's understanding, reducing contemporary grafts to a sort of 'pointing' aimed at their reception (Varagnoli, 2005).

The study of the topos has led to the identification of new routes crossing the most interesting areas, composed of heterogeneous elements, alternating moments of walking and exploring with moments of pause and contemplation. A sort of architectural promenade in which the visitor can immerse himself in the knowledge of the history of the place and where new spatial organizations overlap with those already existing in an experience of upward - not linear - movement, and the stratigraphic complexity of the park finds a new raison d'être $(M R)$.

\section{CONCLUSIONS}

In a contemporary world more and more inclined to oblivion, heritage represents a fundamental element of man's memory. Every pre-existence and every visible sign of the past contribute to constituting the essential environment for its equilibrium and cultural development.

In this sense, protection and conservation activities are essential; moreover, the re-functionalization of buildings or 
areas with historical-artistic value is an important operation to ensure their maintenance and transmission to future generations, avoiding indifference and neglect.

This work has intended to establish an intervention methodology aimed at redeveloping the area of the urban park of the historical centre of Assoro, paying attention, in particular, on the ruins of the castle and on the various archaeological fragments there scattered or still visible in the surrounding areas. The careful analysis carried out through the methodological-operative apparatus of the restoration discipline and based on a rigorous use of the most innovative surveying methods have allowed highlighting the peculiarities of the place, including the important relationship with the natural and anthropological milieu, as well as eloquent and precious traces of its intricate historical stratification.

Such assets, with a high cultural and identity value, possess great potential, unfortunately, today unexpressed due to the lack of preservation, adequate 'exploitation' and appropriate use.

On these assumptions, the proposal put forward by this work, inspired by the thought (albeit purged of any romantic ambition) of John Ruskin who considers the ruins as the extreme sublimity of architecture and favours the idea that the ancient monument goes cured, maintained, and made the object of minimum interventions aimed at extending the life cycle (Ruskin, 1849), has intended to identify, detect and interpret the signs that its life cycle has imprinted in the site.

The aim has been that of drawing up a project, whose main purpose is the preservation and conservation of the material testimonies of the past, encouraging its reading and ensuring its continuity over time.

The program also provides for the functionalization of the area through a global but careful intervention aimed to maintain the authenticity of each element and to valorise them, even by new architectural insertions, changes or modifications in the use functions, in order to return to the population an area now almost abandoned but important for the small Sicilian centre $(A V)$.

\section{ACKNOWLEDGEMENTS}

Laser scanning and photogrammetric surveys were conducted by the Laboratory of Diagnostics and Restoration of Architectural and Cultural Heritage of the Kore University of Enna, in collaboration with the Lab_S.A.B.E. of the University of Bergamo. Michele Russo and Mario Puglisi carried out the UAV survey. Michele Russo has made the drawings.

\section{REFERENCES}

Alagna, A., 2008. Stratigrafia per il restauro architettonico. Il metodo dell'analisi stratigrafica delle superfici murarie per la conoscenza e la conservazione del costruito storico. Aracne, Roma.

Amico, V., 1855. Dizionario Topografico della Sicilia. Palermo.

Arrighetti, A., 2012. Archeologia dell'architettura e ricognizione di superficie nel comune di Sesto Fiorentino (FI). Archeologia dell'architettura, XVII, 173-190.

Balletti, C., Guerra, F. and Adami, A., 2005. 3D multiresolution representations in archaeological sites. CIPA $2005 X X$ International Symposium, Torino, Italy.

Bernabò Brea, L., 1947. Notizie degli scavi di antichità: comunicate alla Accademia dal Ministero per i Beni Culturali e
Ambientali. Atti della Accademia Nazionale dei Lincei, Paris, Louvain, 249-250.

CRICD - Centro regionale per l'inventario, la catalogazione e la documentazione grafica, fotografica, aerofotografica, fotogrammetrica e audiovisiva dei beni culturali e ambientali, ed., 2001. Castelli medievali di Sicilia: guida agli itinerari castellani dell'isola. Regione siciliana, Assessorato dei beni culturali ambientali e della pubblica istruzione, Palermo.

Fallavollita, F., Ugolini, A., 2017. New methodologies for the documentation of fortified architecture in the state of ruins. Int. Arch. Photogramm. Remote Sens. Spatial Inf. Sci., XLII-5/W1, 411-418.

Federman, A., Shrestha, S., Quintero, M., Mezzino, D., Gregg, J., Kretz, S. and Ouimet, C., 2018. Unmanned Aerial Vehicles (UAV) Photogrammetry in the Conservation of Historic Places: Carleton Immersive Media Studio Case Studies. Drones, 2(2), 18.

Foramitti, V., 2004. La Carta di Cracovia e i valori dei castelli. Restauro e riuso dei monumenti fortificati. Atti del convegno internazionale di studi, Messina 8-9 dicembre 2001, 23-28.

Gazzola, P.,1965. Un patrimonio storico da salvare: i castelli. Castellum, 1, 7-16.

Gnolfo, A., 1997. Assoro nella Storia di Sicilia, Catania.

Magnano i San Lio, E., Pagello, E. ed., 2004. Difese da difendere - Atlante delle Città murate di Sicilia e Malta, Fondazione Culturale "S. Sciascia", Caltanissetta.

Morel, J.-P., 1963. Recherches archéologiques et topographiques dans la région d'Assoro (province d'Enna, Sicile). Mélanges d'archéologie et d'histoire, 75(2), 263-301.

Muratore, N., Munafò, P. ed., 1991. Immagini di città raccolte da un frate agostiniano alla fine del XVI secolo, Roma, Istituto poligrafico e Zecca dello Stato.

Purini, F., 1996. Una lezione sul disegno. Roma, Gangemi.

Reiss, M.L.L., da Rocha, R.S., Ferraz, R.S., Cruz, V.C., Morador, L.Q., Yamawaki, M.K., Rodrigues, E.L.S., Cole, J.O. and Mezzomo, W., 2016. Data integration acquired from microUAV and terrestrial laser scanner for the 3D mapping of Jesuit ruins of São Miguel das Missões. Int Arch Photogramm Remote Sens Spat Inf Sci, 41, 315-321.

Ruskin, J., 1849. The Seven Lamp of Architecture, New York: John Wiley.

Santos Silva, A., Adriano, P., Magalhães, A.L., Candeias, A., 2010, Characterization of Historical Mortars from Alentejo's Religious Buildings. International Journal of Architectural Heritage, 4(2):138-154 DOI: 10.1080/15583050903046322

Scudino, D., Billeci, B., Gizzi, S. ed., 2006, Il rudere tra conservazione e reintegrazione. Gangemi Editore, Roma.

Suma, R., Stavropoulou, G., Stathopoulou, E.K., van Gool, L., Georgopoulos, A. and Chalmers, A., 2016. Evaluation of the effectiveness of HDR tone-mapping operators for photogrammetric applications. Virtual Archaeology Review, 7 (15), 54-66.

Varagnoli, C. ed., 2005. Conservare il passato. Metodi ed esperienze di protezione e restauro dei siti archeologici. Gangemi Editore, Roma.

Versaci, A. Cardaci, A., 2011. Integrated survey techniques for the study and the restoration of cultural heritage: some case 
The International Archives of the Photogrammetry, Remote Sensing and Spatial Information Sciences, Volume XLII-2/W11, 2019 GEORES 2019 - 2nd International Conference of Geomatics and Restoration, 8-10 May 2019, Milan, Italy

studies in Enna (Italy). IX International Forum "Le Vie dei Mercanti": S.A.V.E. Heritage Safeguard of Architectural, Visual, Environmental Heritage. Napoli: La scuola di Pitagora, $1-10$. 